\title{
Pre-conditioned mesenchymal stem cells: a better way for cell-based therapy
}

Qing $\mathrm{Li}^{1}$, Yang Wang ${ }^{1}$ and Zhifeng Deng ${ }^{2^{*}}$

See related research by Boopathy et al., http://stemcellres.com/content/4/2/43

\begin{abstract}
Ischemic heart disease is the major cause of death globally, and a recently developed stem cell transplantation is a promising therapy for myocardial infarction. Mesenchymal stem cells (MSCs) exist in a wide range of tissues, and their differentiation potential and immunoregulatory capacity make them a more optimal candidate for regenerative medicine. However, the poor survival and low differentiation efficiency of the donor cells in the infarcted myocardium challenged therapeutic efficacy of MSC transplantation. To this end, many researchers have focused on improving the microenvironments of MSCs before and after transplantation and on trying to figure out the mechanisms. A recent study by Boopathy and colleagues reported the procardiovascular differentiation effect of oxidative stress on cultured MSCs and the underlying signal pathways, leading to the notion that MSCs pre-conditioned with oxidative reagents promote cardiac differentiation efficiency of MSCs and may result in better clinical effect for ischemic heart diseases.
\end{abstract}

Ischemic heart disease is the world's leading cause of morbidity and mortality, and although there are several kinds of therapeutic strategies such as medical, interventional approaches and heart transplantation, the mortality rate of patients with acute myocardial infarction (MI) is still very high. In the past decade, a new strategy called stem cell transplantation has emerged as an effective therapy for preventing heart failure after acute MI. Embryonic stem cells, cardiac progenitor stem cells, and mesenchymal stem cells (MSCs) were all reported to be

\footnotetext{
*Correspondence: dengzf63@126.com

${ }^{2}$ Department of Neurosurgery, Shanghai Jiaotong University Affiliated Sixth

People's Hospital, 600 Yi-Shan road, Shanghai 200233, China

Full list of author information is available at the end of the article
}

able to improve cardiac function after transplanting into the injured heart, and much effort was made to optimize the protocols and reveal underlying mechanisms [1-3]. Among these stem cells, MSCs are the most promising therapeutic approach of cell-based therapy for ischemic heart disease, and its application in heart repair is well studied in pre-clinical and clinical research.

MSCs are responsible for tissue regeneration and homeostasis and exist in almost all tissues and thus can be easily isolated from many tissues. Owing to their multiple differentiation property and immune privilege, MSCs become an attractive candidate for clinical applications. Investigations in animal MI models indicated that MSCs may exert their effect on cardiac repair through the following mechanisms [4]: MSCs can be differentiated into cardiovascular cells to promote cardiac function and neovascularization, can secrete a large amount of angiogenic and anti-apoptotic cytokines to induce endogenous cardiac regeneration and reduce cell apoptosis, and have an immunomodulatory effect and can regulate the microenvironments of the infarcted site. In clinical trials for MI, MSC therapy could improve cardiac function, reduce scar size, and induce reverse remodeling. However, recent evidence indicates that the therapeutic effect of MSC transplantation is not very satisfactory because of the poor viability and massive death of the engrafted MSCs and the low efficiency of differentiation toward myocardial cells in the infarcted myocardium.

After MI, the damaged heart tissue site will be infiltrated with distinct types of inflammatory cells and factors and with substantial amounts of reactive oxygen species (ROS) [5]. The properties of MSCs could be fundamentally influenced by the elements in the complicated milieus and then result in the low viability and differentiation efficiency in tissue repair. Therefore, many studies endeavored to improve cell survival and differentiation by modifying or pre-conditioning the MSCs during the stage of in vitro expansion before transplantation. A study by Boopathy and colleagues [1] in the previous issue of Stem 
Cell Research \& Therapy investigated the effect of the oxidative stress on cardiac differentiation of bone marrowderived MSCs in vitro. The authors mimic the oxidative environment by using hydrogen peroxide $\left(\mathrm{H}_{2} \mathrm{O}_{2}\right)$ or glucose oxidase (GOX) stimulation as a pulse or continuous oxidative stress. Treatments with $\mathrm{H}_{2} \mathrm{O}_{2}$ and GOX at a higher concentration $(100 \mu \mathrm{M}$ and $5 \mathrm{mU} / \mathrm{mL}$, respectively) both resulted in upregulation of early endothelial and cardiac gene expression, and GOX treatment has more significant results. Interestingly, Boopathy and colleagues further showed that the pro-cardiovascular differentiation function of $\mathrm{H}_{2} \mathrm{O}_{2}$ on MSCs is mediated by Notch1 and Wnt11 signaling. Inhibition of Notch signaling abolished the cardiac and endothelial gene expression upon $\mathrm{H}_{2} \mathrm{O}_{2}$ stimulation. Their results indicate that $\mathrm{H}_{2} \mathrm{O}_{2}$ treatment may promote cardiovascular differentiation of MSCs and suggest that injecting $\mathrm{H}_{2} \mathrm{O}_{2}$ pre-conditioned MSCs into infarcted sites may generate more cardiovascular cells to promote cardiac tissue repair.

All of these data provided by Boopathy and colleagues were obtained from in vitro cell culture and chemical treatment; the result needs to be further verified in animal MI models, and time and dose of chemicals used to generate oxidative stress also need to be precisely tested for better result in vivo. A recent report [6] supported their notion that stem cells pre-treated with $\mathrm{H}_{2} \mathrm{O}_{2}$ could improve the therapeutic effect for the infarcted heart. The report showed that $\mathrm{H}_{2} \mathrm{O}_{2}(100 \mu \mathrm{M}$ administered for 2 days) preconditioned cardiac progenitor cells implanted into the left ventricle following ischemia-reperfusion injury led to improved cardiac function, decreased cardiac fibrosis, and higher number of endothelial cells and higher vascular density. Together, these studies suggest that the precondition effect of oxidative reagents on restoring cardiac function and neovascularization of the injured heart is conserved between different kinds of stem cells. However, there is also a controversial conclusion about the effect of ROS on MSC therapy. A previous study [7] showed that treatment of MSCs with $\mathrm{H}_{2} \mathrm{O}_{2}$ decreased the adhesion and spreading of MSCs in vitro and that co-injection of MSCs with free radical scavenger $\mathrm{N}$-acetyl-L-cysteine to infarcted hearts resulted in reduced fibrosis and infarct size. Therefore, it is necessary to find the balance point for ROS treatment and oxygen-free radical scavenging and optimize the experimental procedure accordingly to achieve better clinical effects for ischemic heart disease therapy.

Besides oxidative reagents, many of the growth factors and cytokines are also applied to improve the therapeutic efficacy of MSCs. MSCs pretreated with vascular endothelial growth factor increased cell proliferation, and MSCs treated with transforming growth factor (TGF)- $\alpha$ before being injected into ischemic heart promoted myocardial functional recovery [8,9]. Behfar and colleagues [10] reported that stimulating human MSCs with a cocktail of cytokines, including TGF- $\beta$, bone morphogenetic protein-4, activin A, retinoic acid, insulin-like growth factor-1, $\alpha$-thrombin, and IL-6, induced expression of cardiac transcription factors and that the cardiopoietic human MSCs enhanced therapeutic benefit in an infarcted mice model. Furthermore, the cardiopoietic stem cells were tested in clinical trials for ischemic cardiomyopathy and proved to be safe and effective [11]. Thus, pre-condition of MSCs with proper stimuli has made great advances and appears to be the most promising approach for ischemic heart diseases. It is necessary to get a better understanding of the interaction between MSCs and the microenvironment to have more information for uncovering the mechanisms of MSCmediated therapeutic effects and more practical strategies for clinical use of stem cells.

\section{Abbreviations}

GOX: glucose oxidase: $\mathrm{H}_{2} \mathrm{O}_{2}$ : hydrogen peroxide; IL: interleukin:

MI: myocardial infarction; MSC: mesenchymal stem cell; ROS: reactive oxygen species; TGF: transforming growth factor.

\section{Competing interests}

The authors declare that they have no competing interests.

\section{Author details}

${ }^{1}$ Institute of Limbs Microsurgery, Shanghai Jiaotong University Affiliated Sixth People's Hospital, 600 Yi-Shan road, Shanghai, 200233, China. ²Department of Neurosurgery, Shanghai Jiaotong University Affiliated Sixth People's Hospital, 600 Yi-Shan road, Shanghai 200233, China.

Published: 5 June 2013

\section{References}

1. Boopathy AV, Pendergrass KD, Che PL, Yoon YS, Davis ME: Oxidative stressinduced Notch1 signaling promotes cardiogenic gene expression in mesenchymal stem cells. Stem Cell Res Ther 2013, 4:43.

2. Liu Y, Ye X, Mao L, Cheng Z, Yao X, Jia X, Mao D, Ou L, Li Z, Che Y, Liu N, Steinhoff G, Liu L, Kong D: Transplantation of parthenogenetic embryonic stem cells ameliorates cardiac dysfunction and remodelling after myocardial infarction. Cardiovasc Res 2013, 97:208-218.

3. Williams AR, Hatzistergos KE, Addicott B, McCall F, Carvalho D, Suncion V, Morales AR, Da Silva J, Sussman MA, Heldman AW, Hare JM: Enhanced effect of combining human cardiac stem cells and bone marrow mesenchymal stem cells to reduce infarct size and to restore cardiac function after myocardial infarction. Circulation 2013, 127:213-223.

4. Gnecchi M, Danieli P, Cervio E: Mesenchymal stem cell therapy for heart disease. Vascul Pharmacol 2012, 57:48-55.

5. Ren G, Chen X, Dong F, Li W, Ren X, Zhang Y, Shi Y: Concise review: mesenchymal stem cells and translational medicine: emerging issues. Stem Cells Trans/ Med 2011, 1:51-58.

6. Pendergrass K, Boopathy A, Seshadri G, Maiellaro-Rafferty K, Che PL, Brown M, Davis ME: Acute preconditioning of cardiac progenitor cells with hydrogen peroxide enhances angiogenic pathways following ischemia-reperfusion injury. Stem Cells Dev 2013 [Epub ahead of print].

7. Song H, Cha MJ, Song BW, Kim IK, Chang W, Lim S, Choi EJ, Ham O, Lee SY, Chung $N$, Jang $Y$, Hwang KC: Reactive oxygen species inhibit adhesion of mesenchymal stem cells implanted into ischemic myocardium via interference of focal adhesion complex. Stem Cells 2010, 28:555-563.

8. Penna C, Perrelli MG, Karam JP, Angotti C, Muscari C, Montero-Menei CN, Pagliaro P: Pharmacologically active microcarriers influence VEGF-A effects on mesenchymal stem cell survival. J Cell Mol Med 2013, 17:192-204.

9. Herrmann JL, Wang Y, Abarbanell AM, Weil BR, Tan J, Meldrum DR: Preconditioning mesenchymal stem cells with transforming growth 
factor-alpha improves mesenchymal stem cell-mediated cardioprotection. Shock 2010, 33:24-30.

10. Behfar A, Yamada S, Crespo-Diaz R, Nesbitt JJ, Rowe LA, Perez-Terzic C, Gaussin V, Homsy C, Bartunek J, Terzic A: Guided cardiopoiesis enhances therapeutic benefit of bone marrow human mesenchymal stem cells in chronic myocardial infarction. J Am Coll Cardiol 2010, 56:721-734.

11. Bartunek J, Behfar A, Dolatabadi D, Vanderheyden M, Ostojic M, Dens J, Nakadi BE, Banovic M, Beleslin B, Vrolix M, Legrand V, Vrints C,

Vanoverschelde JL, Crespo-Diaz R, Homsy C, Tendera M, Waldman S, Wijns W, Terzic A: Cardiopoietic stem cell therapy in heart failure: The C-CURE multicenter randomized trial with lineage-specified biologics. J Am Coll Cardiol 2013. doi:10.1016/j.jacc.2013.02.071.

doi:10.1186/scrt213

Cite this article as: Li et al:: Pre-conditioned mesenchymal stem cells: a better way for cell-based therapy. Stem Cell Research \& Therapy 2013 4:63. 